\title{
ОЦЕНКА СОСТОЯНИЯ ПРИБРЕЖНОГО ИХТИОКОМПЛЕКСА ЗАПОВЕДНОЙ АКВАТОРИИ ПРИ ПОМОЩИ ПОДВОДНОГО АВТОНОМНОГО ВИДЕОРЕГИСТРИРУЮЩЕГО УСТРОЙСТВА
}

\author{
Мальцев В.И. ${ }^{1}$, Алексеев А.Н.른 \\ ${ }^{1}$ ФГБУН «Карадагская научная станщия им. Т.И. Вяземского - природный заповедник РАН», \\ 2. Феодосия, Российская Федерация, E-mail: maltsev1356@gmail.com \\ 22. Симферополь, Российская Федерация, E-mail: aaleхиа@ukr.net
}

Нашей целью было создание недорогого, простого в применении подводного автономного видеорегистрирующего устройства (ПАВУ) и проверка его эффективности в режиме тестовой эксплуатации. Наше ПАВУ состоит из следующих элементов: герметичный бокс (металлический цилиндр высотой 200 мм и внутренним диаметром 125 мм, закрывающийся с двух сторон стеклянными крышками $185 \times 185$ мм толщиной 25 мм), автомобильный видеорегистратор с разрешением Full HD (1080p), углом обзора $130^{\circ}$, со штатной картой памяти, батарея $12 \mathrm{~V}$ ёмкостью $7.5 \mathrm{AH}$, металлическая подставка-опора для установки ПАВУ на дно. Тестирование ПАВУ показало его эффективность для учёта пелагических рыб большей части размерного спектра. Качество изображения позволяло однозначно идентифицировать видовую принадлежность рыб, попадающих в поле зрения. Менее эффективен учёт рыб донного комплекса. Рыбы не реагируют на ПАВУ. Получаемая видеоинформация позволяет, кроме прямого учёта численности, судить о поведенческих реакциях рыб в естественной для них среде обитания. На наш взгляд, возможности мониторинга рыб, предоставляемые ПАВУ, свидетельствуют о перспективности его применения для учёта рыб прибрежного ихтиокомплекса, в особенности в сочетании с другими методами учёта. Перспективным выглядит и дальнейшее совершенствование устройства, направленное на расширение его функциональности.

Ключевые слова: подводное автономное видеорегистрирующее устройство, учет рыб, прибрежный ихтиокомплекс

\section{Введение}

Создание объектов особо охраняемых природных территорий, включающих морские или пресноводные акватории, обнаружило необходимость ведения мониторинга биоразнообразия заповедных акваторий, в частности их рыбного населения; эта информация становится неотъемлемой частью Летописи природы.

Мотивом заповедания как правило является наличие на территории (акватории) редких и исчезающих видов растений и животных, изъятие которых противоречит задачам их охраны и воспроизводства. Именно поэтому традиционные методы учёта на заповедных акваториях, к примеру, рыб, основой которых являются ловы при помощи тех или иных приспособлений, считаются неприемлемыми.

Альтернативой традиционным, травматическим методам мониторинга рыбного населения являются бесконтактные, визуальные способы учёта. Можно говорить о визуальных способах учёта, осуществляемых с применением акваланга, либо без такового, когда погружение осуществляется «на задержке дыхания» (Гетман, 2007). Именно таким способом в последнее время и осуществлялась оценка состояния прибрежного ихтиокомплекса Карадагского природного заповедника в Юго-восточном Крыму (Мальцев, Иванчикова, 2015).

(С) В.И. Мальцев , А.Н. Алексеев, 2016

Труды Карадагской научной станции им. Т.И. Вяземского - природного заповедника РАН. - 2016. -Вып. 2 
Со второй половины XX века неоднократно разрабатывались системы подводного видеонаблюдения, в основном для долгосрочных наблюдений (Адрианов и др., 2005, Воom et other, 2014, Маркевич и др., 2015), в том числе для исследования больших глубин, а потому дорогостоящие и сложные в применении.

Нашей целью было создание недорогого, простого в применении подводного автономного видеорегистрирующего устройства (ПАВУ) и проверка его эффективности в режиме тестовой эксплуатации.

Подводное автономное видеорегистрирующее устройство. Мы остановились на варианте создания видеорегистрирующего устройства, дающего возможность наблюдения и учета рыб прибрежного ихтиокомплекса и пелагических макробеспозвоночных посредством видеорегистрации с последующей записью на магнитную карту памяти. Необходимо было обеспечить решение следующих задач:

1. Качественный учет макроорганизмов в зоне действия устройства (распознавание видов).

2. Количественный учет макроорганизмов.

Элементный состав.

Наше подводное ПАВУ состоит из следующих элементов:

- Герметичный бокс (металлический цилиндр высотой 200 мм и внутренним диаметром 125 мм, закрывающийся с двух сторон стеклянными крышками 185×185 мм толщиной 25 мм, стянутыми при помощи 4-х металлических шпилек диаметром 12 мм) (рис. 1).

- Автомобильный видеорегистратор с разрешением Full HD (1080 p), углом обзора $130^{\circ}$, штатной картой памяти и комплектом соединительных проводов (рис. 2).

- Батарея $12 \mathrm{~V}$ ёмкостью 7.5 АН (в нашем случае - батарея от штатного блока бесперебойного питания, одновременно служащего зарядным устройством) (рис. 2).

- Металлическая подставка-опора для установки видеорегистрирующего устройства на дно на высоте 80 см над дном (рис. 3,4$)$.
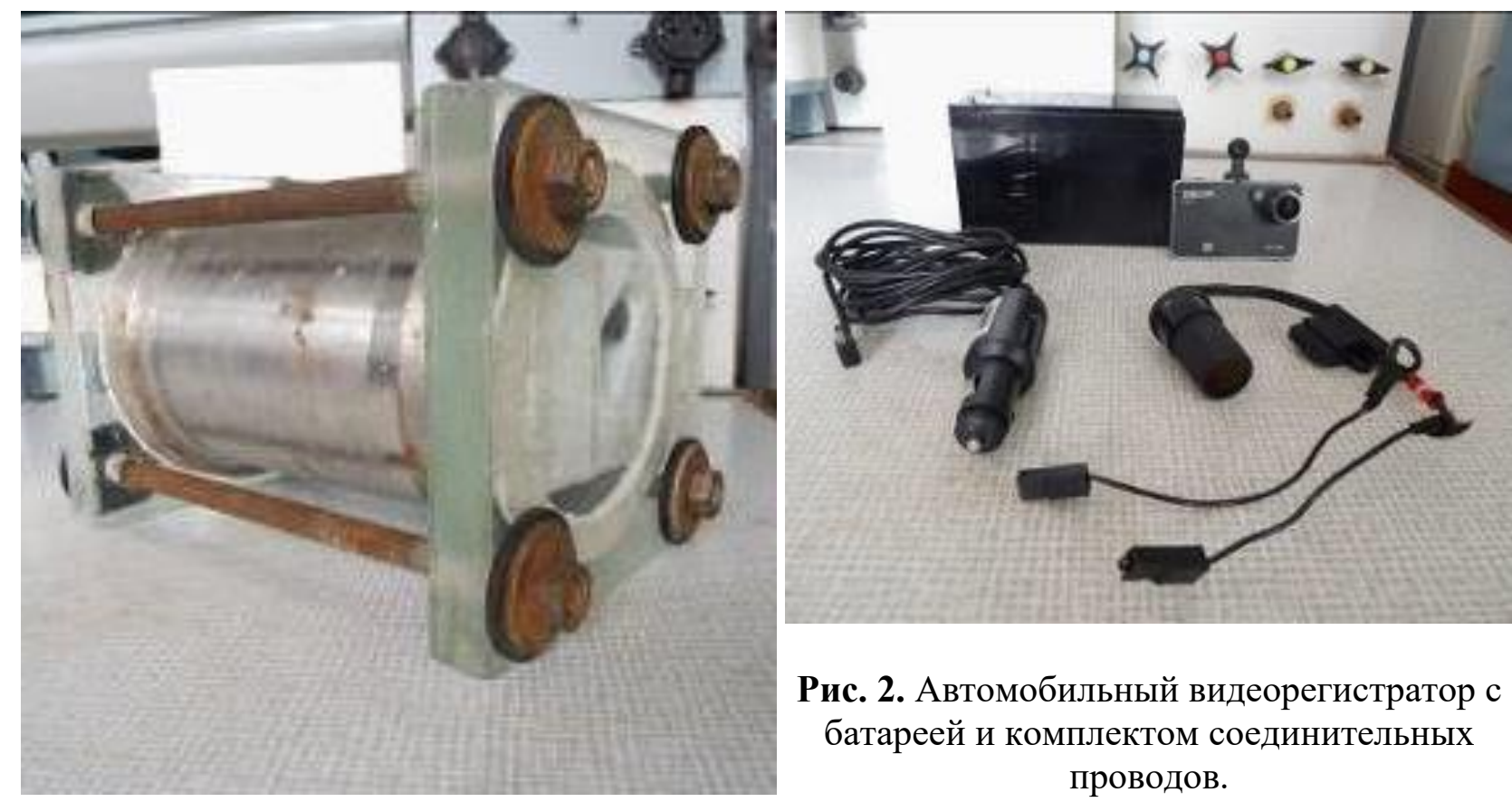

Рис. 2. Автомобильный видеорегистратор с батареей и комплектом соединительных проводов.

Рис. 1. Герметичный бокс ПАВУ. 


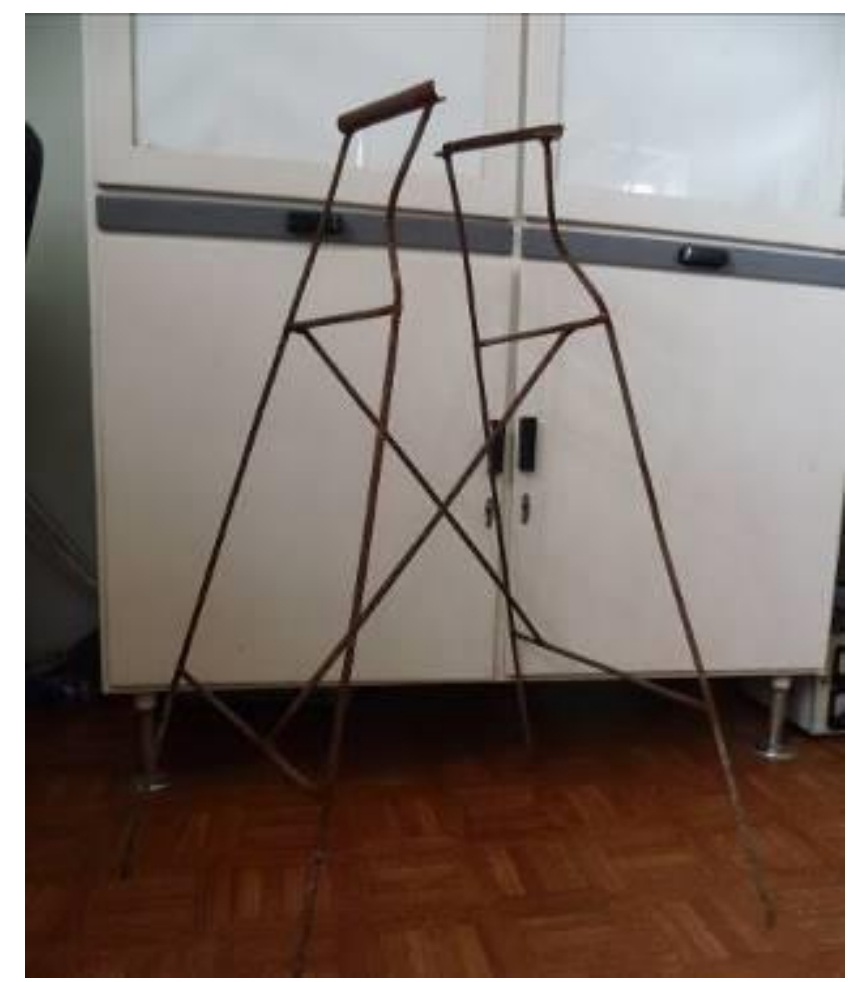

Рис. 3. Подставка для ПАВУ.

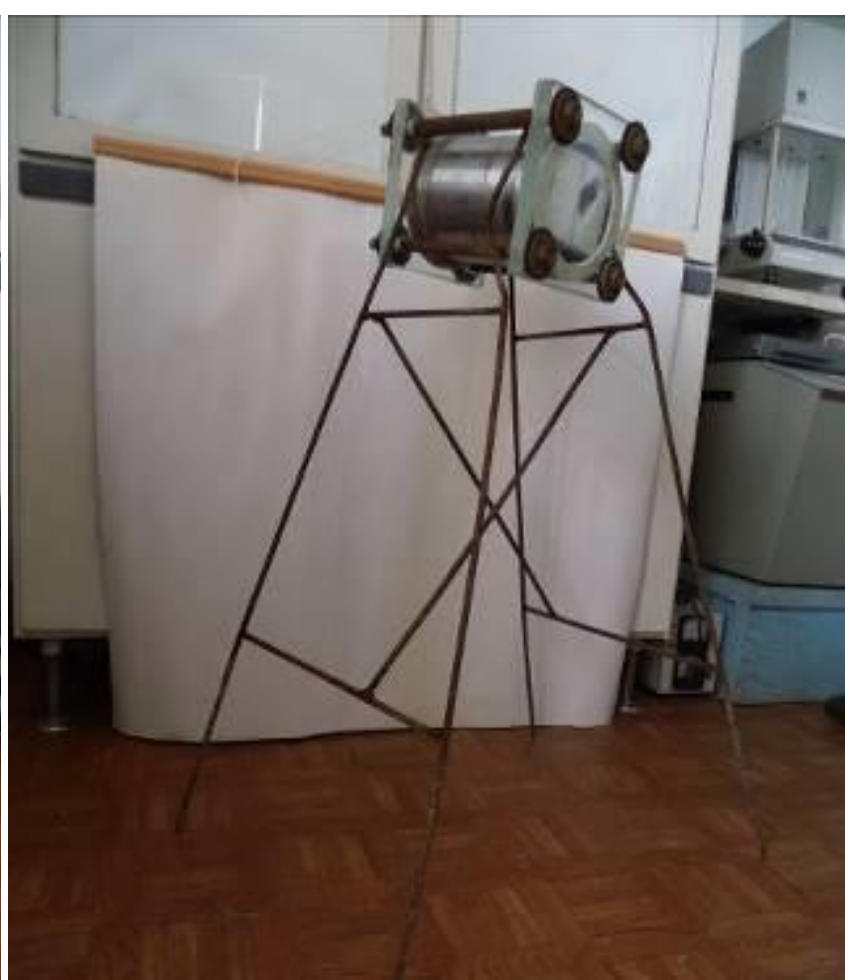

Рис. 4. ПАВУ в сборе.

\section{Материалы и методы}

Тестирование ПАВУ проводили с 9 до 13 часов при солнечной погоде и незначительном (1 балл) волнении либо штиле в июне-июле 2015 г. Район исследования (рис. 5): бухта Карадагская (против усадьбы заповедника), берег которой открыт для посещения, и заповедные акватории у скалы «Золотые ворота», а также в бухте Львиная. Эти акватории характеризуются наличием почти сплошного каменисто-скалистого пояса, сложенного булыжно-галечными наносами (размер камней 10-300 см), образованными в основном породами вулканического происхождения. Песчаные донные отложения у побережья существуют только в виде небольших вкраплений среди нагромождений камней (на отдалении 100-200 м становятся преобладающим типом субстрата).

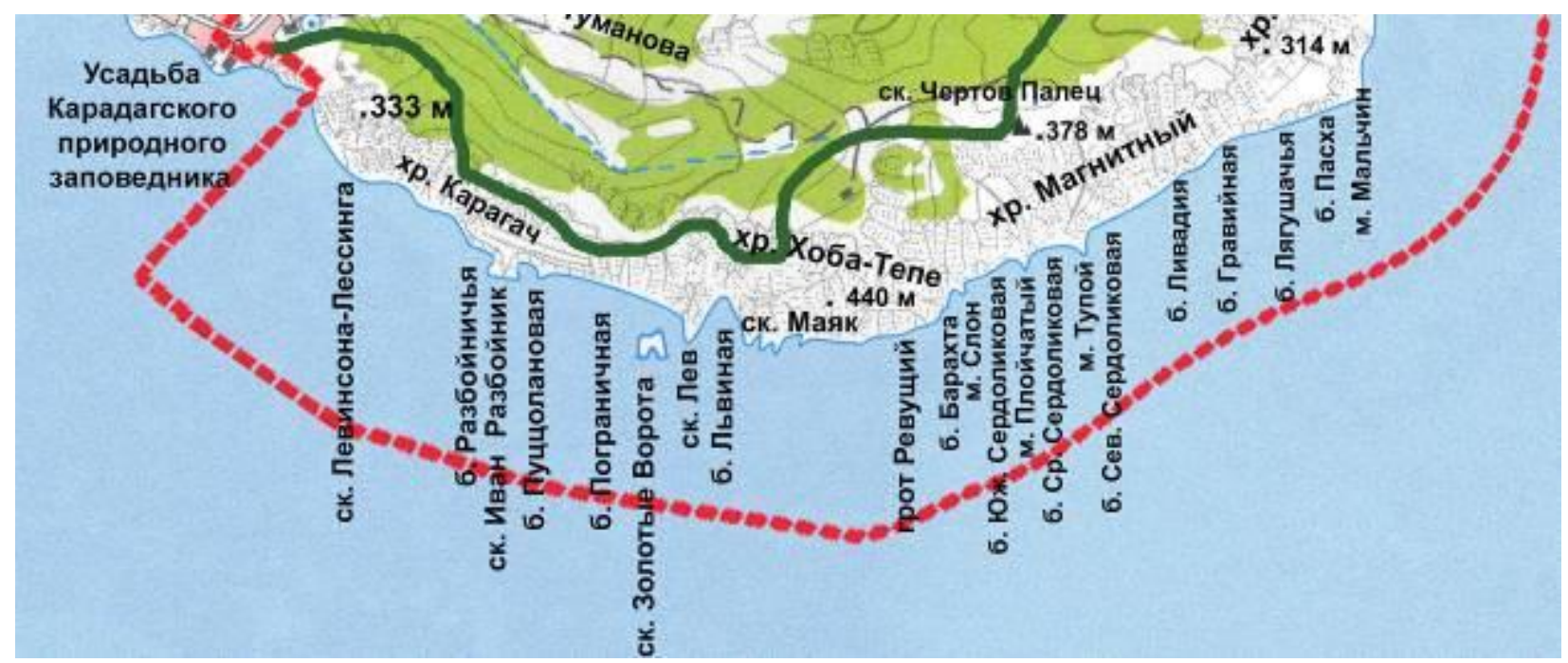

Рис. 5. Район исследования - акватория Карадагского природного заповедника 
Устройство устанавливалось (рис. 6.) на подставке-опоре на дно на глубину 3-5 м, экспозиция составляла от 50 до 100 мин (время экспозиции может быть больше, оно ограничивается емкостью карты памяти). После подъёма ПАВУ карта памяти извлекалась и просматривалась с помощью ПК с соответствующим программным обеспечением.

\section{Результаты}

Определение количества особей того или иного вида, попадающих в поле зрения устройства в течение определённого времени, например, в час, позволяет судить об интенсивности использования рыбами биотопа в момент наблюдения (табл. 1). При этом следует помнить, что при указанной продолжительности экспозиции оседлые рыбы могут попадать в поле зрения не один раз, тем самым увеличивая оцениваемую значимость. В связи с этим мы предприняли попытку обработки информации «по роликам», т. е. подсчёт численности производился по каждому видеоролику (длительностью 5 мин) в отдельности, после чего рассчитывалась средняя численность на 1 ролик (отношение суммарной численности рыб данного вида к количеству роликов), а также отношение количества роликов, где данный вид встречен, к общему количеству роликов в видеоучёте (в \% - своеобразный аналог встречаемости). При этом мы приняли допущение, что повторными появлениями одних и тех же особей в поле зрения видеорегистратора (после их выхода за пределы поля зрения) в течение длительности ролика можно пренебречь.

Таблица 1.

Некоторые результаты учёта рыб прибрежного ихтиокомплекса в акватории Карадагского природного заповедника с помощью ПАВУ (расчетная численность рыб, попавших в поле зрения ПАВУ в час)

\begin{tabular}{|c|c|c|c|c|}
\hline \multirow{2}{*}{ Виды } & \multicolumn{2}{|c|}{ Бухта биостанции } & \multirow{2}{*}{$\begin{array}{c}\text { У скалы Золотые } \\
\text { Ворота }\end{array}$} & \multirow{2}{*}{$\begin{array}{c}\text { Львиная бухта } \\
31.07 .2015\end{array}$} \\
\hline & 09.06 .2015 & 10.07 .2015 & & \\
\hline Кефали (до вида не определны) & & & 40,0 & 36,9 \\
\hline Atherina boyeri Risso, 1810 - атерина & 2,4 & 3,3 & 14,2 & \\
\hline $\begin{array}{l}\text { Diplodus annularis Linnaeus, } 1758 \text { - ласкирь } \\
\text { (карась морской) }\end{array}$ & 57,6 & 58,7 & 7,4 & \\
\hline Diplodus puntazzo (Cetti, 1777) - зубарик & & & 1,9 & 12,6 \\
\hline $\begin{array}{l}\text { Sciaena umbra Linnaeus, } 1758 \text { - горбыль } \\
\text { тёмный }\end{array}$ & & & & 0,4 \\
\hline Mullus barbatus Linnaeus, 1758 - султанка & & 0,6 & & \\
\hline Crenilabrus tinca (Linnaeus, 1758) - рулена & 124,8 & 120,7 & 208,4 & 70,1 \\
\hline $\begin{array}{l}\text { Crenilabrus ocellatus (Forsskål., 1775) - губан } \\
\text { глазчатый }\end{array}$ & 8,4 & 59,3 & 89,7 & \\
\hline $\begin{array}{l}\text { Parablennius sanguinolentus (Pallas, 1814)- } \\
\text { морская собачка обыкновенная }\end{array}$ & 14,4 & 11,4 & 1,9 & 7,2 \\
\hline Сеголетки (до вида не определны) & & 50 & & \\
\hline
\end{tabular}


Для дальнейшей формализации обработки полученных данных мы разбили на интервалы величины «встречаемости» и средней численности, каждому из которых присвоили бальную оценку (табл. 2):

\section{Бальные оценки величины «встречаемости» и средней численности рыб в пересчёте на 1 ролик}

Таблица 2.

\begin{tabular}{|c|c|c|c|}
\hline $\begin{array}{c}\text { «Встречаемость», } \\
\text { интервал }\end{array}$ & $\begin{array}{c}\text { Оценка в } \\
\text { баллах }\end{array}$ & $\begin{array}{c}\text { Средняя } \\
\text { численность, } \\
\text { интервал }\end{array}$ & Оценка в баллах \\
\hline До $10,0 \%$ & 1 & До 2,0 & 1 \\
\hline $10,1-25,0 \%$ & 2 & $2,1-5,0$ & 2 \\
\hline $25,1-50,0 \%$ & 3 & $5,1-10,0$ & 3 \\
\hline $50,1-75,0 \%$ & 4 & $10,1-15,0$ & 4 \\
\hline $75,1-100,0 \%$ & 5 & $>15,0$ & 5 \\
\hline
\end{tabular}

Суммируя бальные оценки для каждого вида получаем формализованную характеристику его значимости в данном биотопе. В зависимости от «набранных» видом баллов можно также присвоить ему одну из категорий (вербальных характеристик):

- Малочисленный вид - до 3-х баллов;

- Обычный вид - 4-7 баллов;

- Массовый вид - 8-10 баллов.

Полученные таким образом данные сведены в табл. 3 .

Есть также возможность производить оценку обилия рыб на единицу пространства. Для определения площади дна, над которым производится учет, на дно выставляются вешки на расстоянии 5, 10 или 15 м в зависимости от прозрачности воды, позволяющей идентифицировать вид организма, попавшего в поле зрения, и оценить его размер (принадлежность к размерному классу, см. выше). Расчет производится как площадь сектора с известным (заданным) радиусом и углом обзора (в нашем случае $130^{\circ}$ ):

$$
S=\frac{\pi r^{2} 130^{\circ}}{360^{\circ}}
$$

где $\mathrm{S}$ - площадь сектора, $\mathrm{r}$ - радиус круга (сектора).

Этот способ оценки обилия мы планируем осуществить в дальнейшем.

Заметим также, что ПАВУ дает возможность оценить проводить видеоучёт планктонных макробеспозвоночных (табл. 4, рис. 10). 


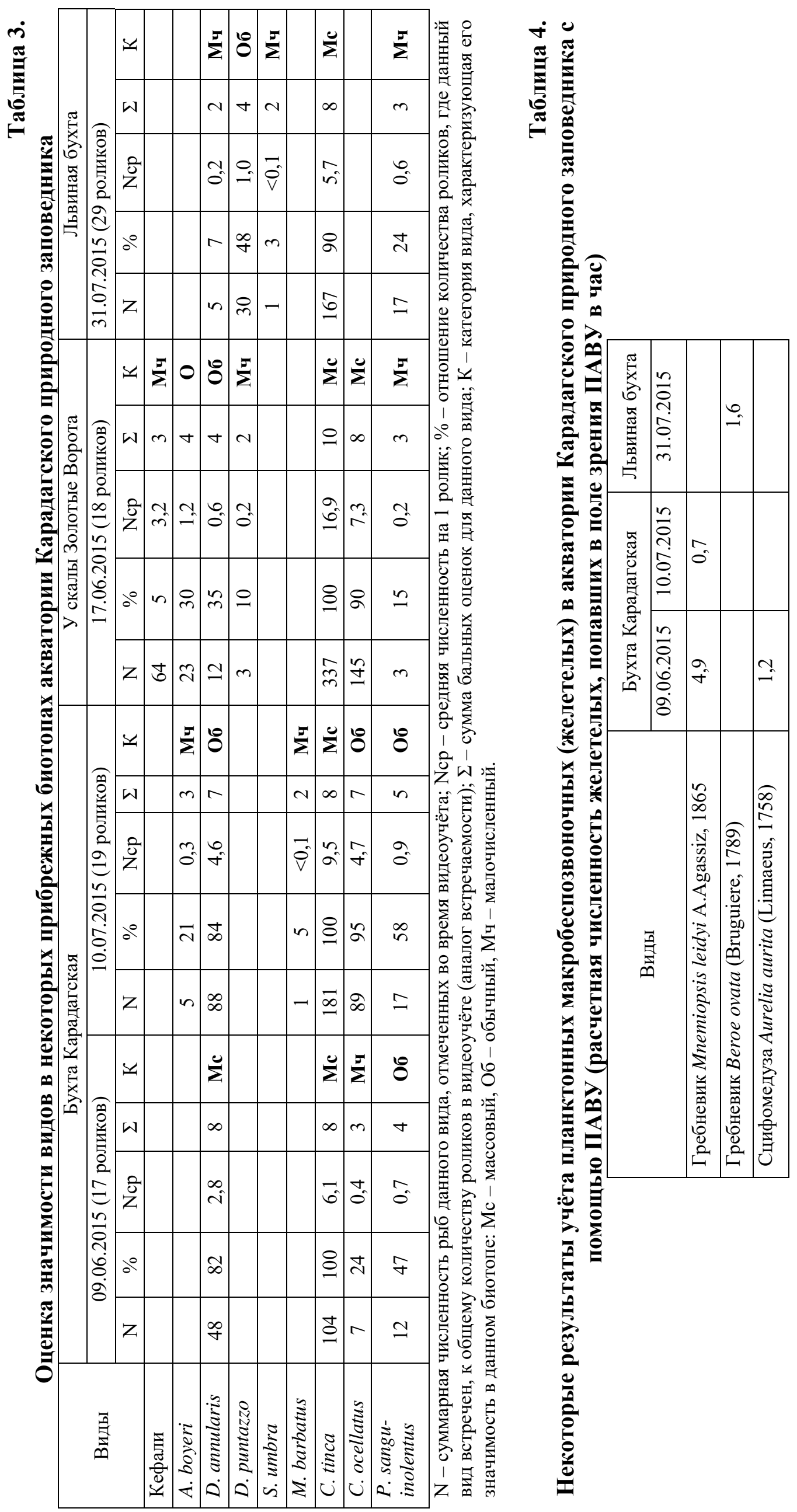




\section{Обсуждение}

Тестирование ПАВУ показало его эффективность для учёта пелагических рыб большей части размерного спектра (табл. 1). При этом в абсолютном большинстве случаев качество изображения позволяло однозначно идентифицировать видовую принадлежность рыб (и желетелых), попадающих в поле зрения (рис. 7-10). После соответствующей обработки полученных с помощью ПАВУ данных и их корректной интерпретации (табл. 1, 3 , 4) можно получать адекватные качественные и количественные характеристики присутствующих в районе исследований видов пелагических рыб и желетелых. Менее эффективен учёт рыб донного комплекса вследствие того, что они попадают на периферию поля зрения устройства, где качество изображения несколько снижено.

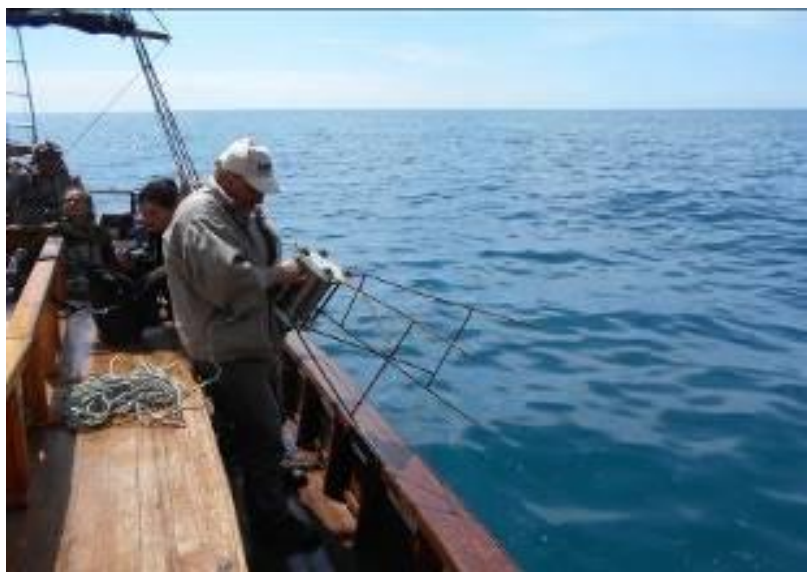

Рис. 6. Установка ПАВУ с борта теплохода (фото Ю.А. Подунай).

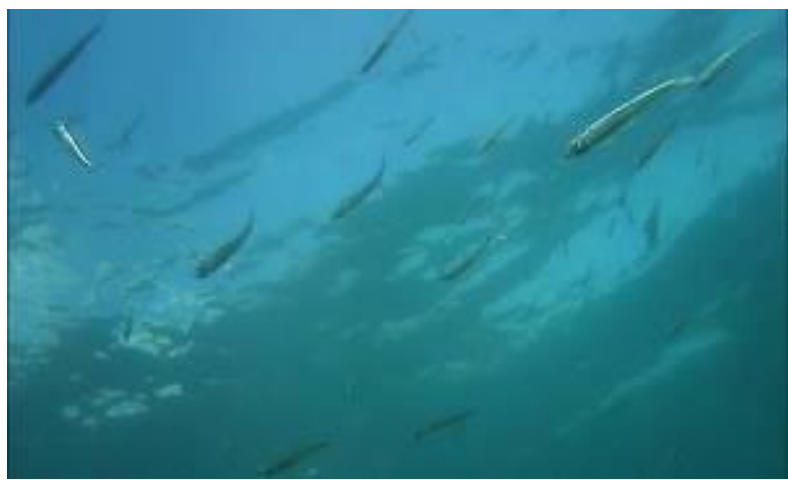

Рис. 8. Атерины в поле зрения ПАВУ.

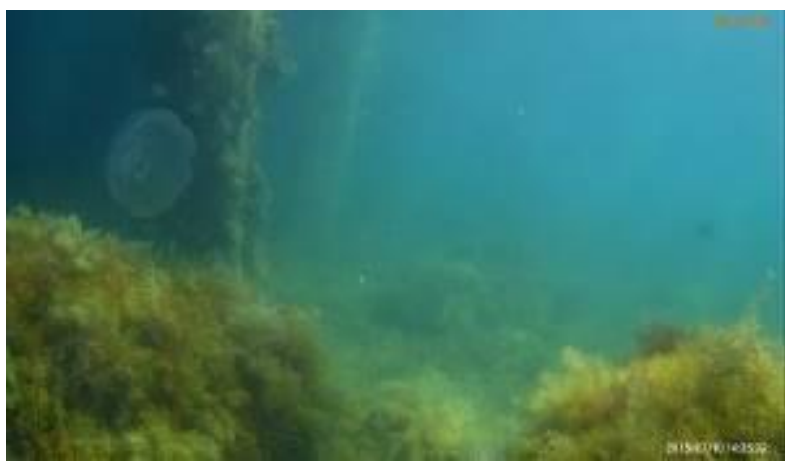

Рис. 10. Медуза аурелия.

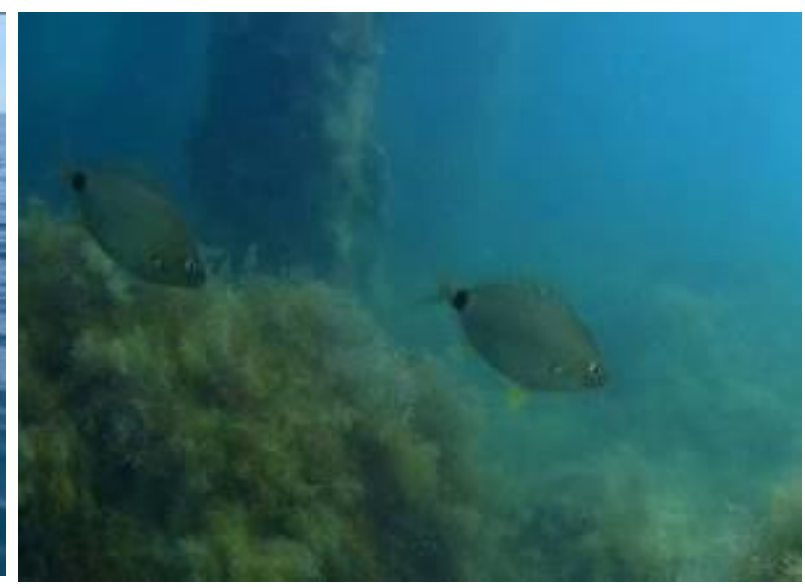

Рис. 7. Ласкири в поле зрения ПАВУ.

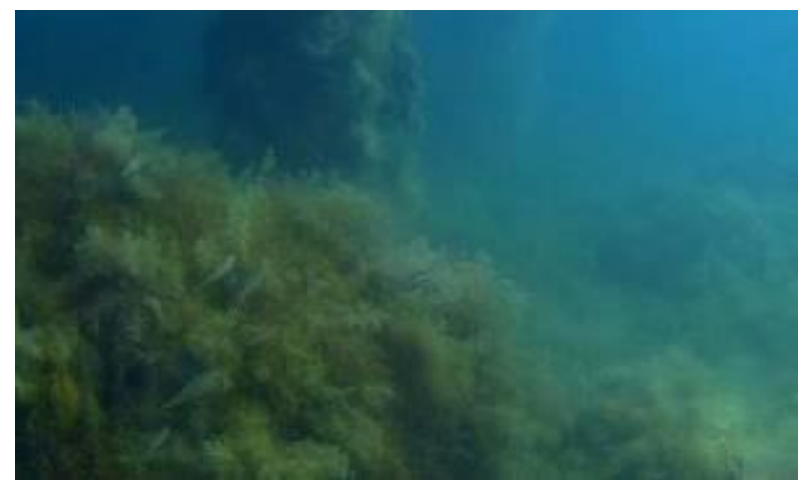

Рис. 9. Зеленушки среди зарослей цистозиры.

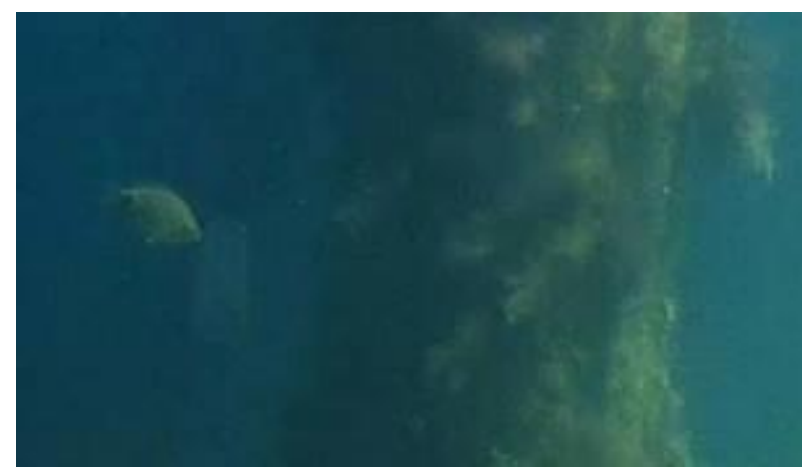

Рис. 11. Ласкирь, обкусывающий гребневика. 
Рыбы не реагируют на ПАВУ. В этой связи можно констатировать, что получаемая видеоинформация позволяет, кроме прямого учёта численности, судить о поведенческих реакциях рыб в естественной для них среде обитания, как, например, объедание гребневика ласкирем (рис. 11).

\section{Заключение}

На наш взгляд, возможности мониторинга рыб, предоставляемые ПАВУ, свидетельствуют о перспективности его применения для учета рыб прибрежного ихтиокомплекса, в особенности в заповедных акваториях. Использование ПАВУ в сочетании с другими методами учета (там, где это возможно) повысит достоверность получаемой информации. Перспективным выглядит и дальнейшее совершенствование устройства, направленное на расширение его функциональности, в особенности для улучшения эффективности учёта донных рыб и беспозвоночных.

\section{Список литературы}

1. Адрианов А.В., Тарасов В.Г., Щербатюк А.Ф. Применение и перспективы сезонного видеомониторинга на особо охраняемых морских акваториях залива Петра Великого // Вестн. ДВО РАН. 2005. № 1. С. 19-26.

2. Гетман Т.П. Визуальные подводные наблюдения при оценке качественноколичественных показателей ихтиоцена // Экология моря. 2007. Вып. 74. С. 13-17.

3. Мальцев В.И., Иванчикова Ю.Ф. Прибрежный ихтиокомплекс акватории Карадагского природного заповедника (Чёрное море, Крым) // 100 лет Карадагской научной станции им. Т.И. Вяземского. Сборник научных трудов. Симферополь, Н. Оріанда. 2015. С. 584-589.

4. Boom B.J., Jiyin He J., Palazzo S., Huang P.X., Beyan C., Chou H.-M., Lin F.-P., Spampinatto C., Fisher R.B. A research tool for long-term and continuous analysis of fish assemblage in coral-reefs using underwater camera footage // Ecol. Informatics. 2014. Vol. 23. P. 83-97.

Поступила 27 июля 2016 г. В окончательном виде 16 ноября 2016 г.

\section{ESTIMATION OF STATE OF THE LITTORAL ICHTHYO-COMPLEX AT THE AQUATORIUM OF PROTECTED AREA WITH SUBMERGED SELF-CONTAINED VIDEORECORDING DEVICE \\ Maltsev V.I. ${ }^{1}$, Alekseyev A.N. ${ }^{2}$ \\ ${ }^{\text {I}}$ T.I. Vyasemsky Karadag Research Station - Nature Reserve of the RAS, Feodosia, Russian Federation, E-mail:maltsev1356@gmail.com \\ ${ }^{2}$ Simferopol, Russian Federation, E-mail: aalexua@ukr.net}

Our aim was creation of inexpensive, simple in application submerged self-contained videorecording device and verification of its efficiency in the mode of test using. Our videorecording device consists of following elements: leakproof container (metallic cylinder as high as $200 \mathrm{~mm}$ with internal diameter $125 \mathrm{~mm}$, closed both-side by glass lids $185 \times 185 \times 25 \mathrm{~mm}$ ), motor-car Full HD (1080p) videorecorder with corner of review $130^{\circ}$, with a regular memory card, battery $12 \mathrm{~V}$ with capacity $7.5 \mathrm{AH}$, and metallic support for setting device on bottom. Testing of the videorecording device showed its efficiency for the count of pelagic fishes of greater part of size spectrum. Quality of image allowed to identify species belonging of fishes getting in eyeshot. The count of bottom associated fishes is less effective. Pisces do not react on upon the device. The got video information makes possible both direct count of quantity and having notion about behavior reactions of fishes in a natural for them habitat. Tested possibilities of monitoring of fishes with our videorecording device show perspectives of its application for count of littoral fishes in particular in combination with other methods of count. The further improvement of device for expansion of its functionality looks perspective.

Key words: submerged self-contained videorecording device, count of fishes, littoral ichthyo-complex 